\title{
Ultraje do rosto: embates discursivos e reconhecimento da liderança feminina na Petrobras
}

Facial outrage: discursive clashes and recognition of female leadership in Petrobras

El ultraje del rostro: enfrentamientos de los discursos y reconocimiento del liderazgo femenino en Petrobras

Ângela Cristina Salgueiro Marques

- Pós-doutora em Comunicação pela Université Stendhal - Grenoble III, França

- Doutora em Comunicação Social pela Universidade Federal de Minas Gerais (UFMG)

- Mestre em Comunicação Social pela UFMG

- Graduada em Jornalismo pela UFMG

- Professora do Programa de Pós-graduação da UFMG

- Organizadora e co-organizadora de uma série de obras

- E-mail: angelasalgueiro@gmail.com

\section{Frederico da Cruz Vieira de Souza}

- $\quad$ Doutorando em Comunicação Social na Universidade Federal de Minas Gerais (UFMG)

- Mestre em Comunicação Social pela UFMG

- Graduado em Jornalismo e em Relações Públicas pela UFMG

- Especialista em Administração de Empresas pela Fundação Getúlio Vargas (FGV)

- Relações-públicas da Assembleia Legislativa do Estado de Minas Gerais

- $\quad$ Foi relações-públicas da Petrobras (2006-2009)

- E-mail: frederico.vieira.souza@gmail.com 


\section{ANO 13 • NÚMERO 24 • 1은. 2016 • ORGANICOM \\ ULTRAJE DO ROSTO: EMBATES DISCURSIVOS E RECONHECIMENTO DA LIDERANÇA FEMININA NA PETROBRAS}

\section{Resumo}

Discursos organizacionais e questões do processo de afirmação e reconhecimento das identidades femininas no mundo corporativo são o foco desseartigo. Abordam-se dimensões dos dilemas antifeministas envolvidos nos discursosorganizacionais, em distintos momentos e mediados por diferentes suportes de comunicação. Valendo-se de aparições da liderança feminina no espaço público, elegemos como norteadores conceituais as noções de rosto e de ultraje para embasar uma breve análise comunicacional sedimentada no rosto de Graça Foster, primeira mulher presidente da Petrobras. A metodologia híbrida desenvolvida para a leitura qualitativa das produções midiáticas em questão alia elementos da análise do discurso a outros próprios da semiótica, considerando as dimensões ética e estético-expressiva das textualidades e imagens constantes nas produções analisadas. Os resultados alcançados apontam para a necessidade de uma visão crítica da comunicação organizacional que prime pela ética, abandonando estereotipias usualmente empregadas pelos discursos organizacionais, sobretudo por aqueles que tematizam as mulheres.

\section{PALAVRAS-CHAVE: DISCURSO・RECONHECIMENTO・ROSTO・LIDERANÇA FEMININA・PETROBRAS・GRAÇA FOSTER}

\section{Abstract}

Organizational speeches and issues concerning the process of affirmation and recognition of women's identities in the corporate world are the focus of this article. They address the dimensions of the anti-feminist dilemmas involved in the organizational speeches, at different moments and mediated by various communication media. Drawing on the apparition of feminine leadership in the public space, we have chosen as conceptual guides of the facial and notional outrage as a basis for a brief communicational analysis sedimented on Graça Foster's face, the first woman to occupy the presidency of Petrobras. The hybrid methodology developed for a qualitative reading of the mediatic productions in the matter joins the elements of the analysis of the discourse with others that are proper of the semiotics, considering the ethical and aestheticexpressive dimensions of the textualities and images contained in the productions analyzed. The results achieved point to the need for a critical view of organizational communication that values ethics, abandoning the stereotypes usually used in organizational discourses, especially those that use women as themes.

\section{KEYWORDS: DISCOURSE・RECOGNITION •FACE・WOMEN'S LEADERSHIP•PETROBRAS・GRAÇA FOSTER}

\section{Resumen}

Discursos organizacionales y cuestiones del proceso de afirmación y reconocimiento de las identidades femeninas en el mundo corporativo son el foco de este artículo. Se abordan dimensiones de los dilemas antifeministas envueltos en los discursos organizacionales, en distintos momentos y mediados por diferentes suportes de comunicación. Valiéndose de apariciones del liderazgo femenino en el espacio público, elegimos como directoras conceptuales las nociones de rostro y de ultraje para fundamentar un breve análisis comunicacional sedimentado en el rostro de Graça Foster, primera mujer presidente de la Petrobras. La metodología híbrida desarrollada para la lectura cualitativa de las producciones mediáticas en cuestión reúne elementos del análisis del discurso a otros propios de la semiótica, considerando las dimensiones ética y estéticoexpresiva de las textualidades e imágenes constantes en las producciones analizadas. Los resultados alcanzados apuntan para la necesidad de una visión crítica de la comunicación organizacional que prime por la ética, abandonando estereotipias usualmente empleadas por los discursos organizacionales, sobre todo por aquellos que tematizan a las mujeres. 


\section{ANO 13 • NÚMERO 24 • 1은. 2016 • ORGANICOM \\ ULTRAJE DO ROSTO: EMBATES DISCURSIVOS E RECONHECIMENTO DA LIDERANÇA FEMININA NA PETROBRAS}

II Não conheço homens tão firmes como a vida me fez ser", afirmou a então presidente da Petróleo Brasileiro S.A., a Petrobras', Maria das Graças Foster, à revista Você $S / A$, em abril de 2013. 0 porvir a desafiaria com uma crise sem precedentes na história da empresa, sobremaneira motivada pelas investigações da Operação Lava-Jato da Polícia Federal e pelaCPI (Comissão Parlamentar de Inquérito) ${ }^{2}$ da Petrobras. Os escândalos de corrupção e o declínio de credibilidade da empresa culminaram em sua perda de valor de mercado, levando Graça Foster e toda a diretoria executiva à renúncia dos cargos em fevereiro de 2015. Nesse processo, foi necessário mais que uma firmeza masculina por parte de Graça, mas (numa provocação!) resignação feminina perante a impossibilidade de permanência na presidência.

No presente artigo arriscamos esboçar uma análise que não enfoca as causas e os efeitos da ascensão, do apogeu e da queda de Graça como liderança máxima da Petrobras, nem desenvolvemos juízos morais ou justificações para acusar ou defender a sua gestão. Nosso olhar se volta para a expressividade do feminino, encarnado na figura pública de Graça, investigando deslocamentos possíveis do olhar que nos façam perceber os embates entre discursos presentes no contexto organizacional e a precarização do feminino resultante desse fenômeno comunicacional, desnaturalizando-se os limites entre territórios de sentido eivados por estereótipos, como o são firmeza masculina e a resignação feminina.

\section{MULHERES, DISCURSOS E ORGANIZAÇÕES}

Há muito se fazem presentes no espaço público diferentes discursos construídos pelas organizações sobre as mulheres e suas condições de vida, discursos especialmente projetados pelas práticas corporativas de comunicação. Esses discursos não se referem estritamente a aspectos do mundo do trabalho, mas também a como a presença do feminino no ambiente organizacional se desdobra em relações que tais organizações estabelecem com a sociedade e com os seus diferentes segmentos de públicos. Por vezes esses discursos divergem, gerando, com isso, espaço para abertura e transformação da cena organizacional ou, de modo inverso, o recrudescimento de aspectos pouco democráticos como preconceitos e crenças totalizantes.

Nesse contexto cabe distinguir conceitualmente os termos organizacional e corporativo. 0 primeiro, mais amplo que 0 segundo, abrange todos processos e produtos de comunicação vinculados a quaisquer organizações, sejam elas empresas, instituições públicas ou do terceiro setor. Já o termo corporativo refere-se à área de corporate affairs, como é denominada a comunicação corporativa nas empresas internacionais, "uma função da administração que ajuda a organização a construir uma reputação favorável no processo de relacionamento com seus públicos" (Silva Neto, 2013). A comunicação corporativa procura atuar estrategicamente no quadro ampliado da comunicação organizacional, articulada a outros segmentos da empresa ou corporação, como são a propaganda, a comunicação interna e os relacionamentos com os investidores, 0 governo e a mídia, entre outros públicos.

Assim, os discursos organizacionais, e dentre eles aqueles de matriz corporativa, constroem publicamente diferentes sentidos sobre as noções de feminino e dos papéís das mulheres nas organizações. Em que pesem as agruras oriundas dos dilemas que aqui enfocamos, seja na iniciativa privada, nas instituições públicas ou nas organizações da sociedade civil, observa-se um avanço, mesmo que lento e em diferentes níveis, no atendimento às demandas trazidas à esfera pública pelos

1 Petroleira de capital aberto cujo acionista majoritário é o Governo do Brasil (União). É uma empresa estatal de economia mista com presença em todo o país e no exterior. A indicação de nomes para sua presidência é feita pelo chefe do Poder Executivo Federal.

2 "A CPI da Petrobras foi instalada por iniciativa de parlamentares de oposição (ao governo Dilma) em decorrência de diversas denúncias envolvendo a Petrobras. Em março de 2014, quando a operação Lava-Jato, da Polícia Federal, revelou relações entre o doleiro Alberto Youssef e Paulo Roberto Costa, ex-diretor de Abastecimento da Petrobras, a gestão da estatal foi posta à prova, já que os dois foram presos em uma investigação de um esquema de lavagem de dinheiro que movimentou R\$ 10 bilhões". Fonte: http://exame.abril.com.br/brasil/noticias/o-que-ja-se-sabe-sobre-o-escandalo-envolvendo-a-petrobras. Acesso em 12/07/2015. 
movimentos feministas do século XX33. Tais movimentos são protagonistas de uma luta por reconhecimento (Honneth, 2003) que, no momento político e social contemporâneo, revela novos matizes tensionados pelas multiplicidades de identidades de gênero e pelas alteridades envolvidas no processo de construção da autonomia política e social das mulheres, leitmotiv das atuais políticas pró-equidade, excedendo-se o estreito binômio feminino versus masculino. Importante lembrar que a noção de igualdade é sempre algo a ser problematizado em processos de negociação linguageiros e políticos que envolvam conflitos morais e de gênero. Nas últimas décadas, a própria noção de feminino se deslocou da exclusividade do substantivo mulher para ocupar, nos discursos que circulam e se enfeixam no espaço público, outras fronteiras.

Nesse cenário de considerável complexidade, desenrolam-se os discursos organizacionais, tanto sobre mulheres quanto sobre o feminino. Cada organização, a seu modo, posiciona-se perante essa luta pelo reconhecimento empreendida por grupos e coletivos feministas. Mesmo o silêncio organizacional ou a alienação institucional sobre as necessidades de se estabelecerem novos padrões de relacionamento com o público feminino já constituem um tipo de posicionamento. 0 discurso organizacional delimita sempre territórios de produção de sentido, tanto para os públicos, como para a própria organização. As perspectivas de Mikhail Bakhtin (1981; 2000) e Norman Fairclough (2001) nos auxiliam a compreender as possíveis articulações entre os elementos linguísticos (imagens, palavras e outros signos sensoriais) presentes nas manifestações publicizadas pelas organizações em diferentes tipos de mídia, internas ou externas ao sistema organizacional, e na abordagem das questões afeitas ao universo das mulheres.

Os embates discursivos apontam para o surgimento de subjetividades para além do si (organização falando sobre e para ela mesma) rumo às alteridades marcadas por danos ou pelo reconhecimento das diferenças de gênero (no âmbito do próprio discurso e na construção das relações entre sujeitos e a organização). A compreensão dos "tipos relativamente estáveis de enunciados" (Bakhtin, 2000), em que diferentes vozes podem ser percebidas levando à interdiscursividade, pode oferecer mais que um mapa das trilhas discursivas que por vezes são conflitantes entre si, mas sintetizar modos de aparecer e dizer das organizações e de seus públicos sobre dada questão, mesmo que para além do visto e do dito.

Fairclough (2001) avança um pouco nessa direção ao integrar uma variedade de perspectivas e métodos de análise para estudar as dimensões discursivas da mudança social. Para 0 autor, a conexão entre o discurso e as práticas sociais é afetada por uma hegemonia do modo de ver e pensar presente nas práticas sociais. Há relações de poder que variam do mais tenaz assujeitamento à autonomia, as quais reproduzem, reestruturam ou desafiam as hegemonias existentes. Um exemplo de pensamento hegemônico concernente à compreensão do feminino e das mulheres no mundo do trabalho é a de que "lideranças femininas são mais comunicativas, intuitivas e acolhedoras", estabelecendo as balizas para o reforço do estereótipo da mulher "auxiliadora e compreensiva". Esse olhar oculta um modo de ver e pensar que faz contrapor 0 masculino "racional, viril e dominador" a feminino "emocional, dócil e passivo". Mesmo respeitáveis teóricos da comunicação organizacional como Gareth Morgan (1996) resvalam em estereótipos. Na obra Imagens da organização, o autor apresenta um rol de "estratégias femininas populares", das quais destacamos as duas seguintes: "Rainha Elizabeth I - Reina com mãos firmes, tendo sempre que possível à sua volta homens dóceis (...). A mulher invisível - Tem um perfil inexpressivo; tenta misturar-se com os que estão à sua volta, exercendo a sua influência de todas as formas possíveis" (Morgan, 1996, p. 187).

3 No Brasil, de acordo com estudo realizado e divulgado em março de 2015 pelo Instituto Brasileiro de Geografia e Estatística (IBGE), as mulheres, embora sejam maioria da população e apresentem maior nível de escolaridade que os homens, recebem remunerações inferiores a eles, mesmo quando ocupam os mesmos cargos. Nas organizações, o público feminino situa-se, com maior frequência, em postos de trabalho inferiores da hierarquia. De acordo com relatório do Observatório Brasil da Igualdade de Gênero, as mulheres são minoria nos cargos de maior nível hierárquico no Parlamento, nos governos municipais e estaduais, nas secretarias do primeiro escalão do Poder Executivo, no Judiciário, nos sindicatos e até nas reitorias. No setor privado, o quadro permanece o mesmo; várias pesquisas realizadas pelo Observatório confirmam a proporção de $20 \%$ a $30 \%$ de mulheres nos postos de chefia. Fonte: http://www.observatoriodegenero.gov.br/menu/noticias/noticias. Acesso em 24/05/2015. 
0 discurso das organizações - e a respeito delas - pode, no entanto, reestruturar ou desafiar ordens hegemônicas. Esse é um dos focos das organizações que, em suas políticas corporativas de gestão, promovem a liderança feminina; procuram valorizar a singularidade da gestora em seu lugar de poder e operar mudanças que vão além do discurso, amparadas na efetiva garantia de cotas ou número de assentos femininos nas hierarquias mais elevadas. Nesse contexto, é esperado que a comunicação corporativa apele estrategicamente não apenas às imagens das mulheres, mas às vozes e expressões do feminino dentro das organizações e nas ações externas a elas.

Assim a conhecida comunicação corporativa "feita para mulheres" ou que discursa "sobre as mulheres" ou, ainda, "sobre o feminino" deve ser considerada partícipe de um sistema discursivo que as organizações "vivem" no espaço público, em que agem e sofrem enunciações discursivas dos outros a seu respeito, sejam as midiáticas tradicionais (jornais, revistas, tv...), sejam aquelas publicizadas pelos múltiplos sujeitos presentes nas redes sociais online.

Ao remeterem continuamente uns aos outros, os discursos conformam uma teia vazada por "entres". Acreditamos que é nesse espaço intersticial que se revela o não visto e o não dito sobre os interlocutores, ou ainda o que está por dizer. E nisso o conceito de rosto, de Emmanuel Lévinas, pode muito ajudar, ao nos conduzir a esse além-do-discurso, que desvela dimensões outras dos processos de subjetivação feminina imbricados nos meandros da comunicação corporativa, da comunicação organizacional e, para além delas, na extensão do espaço público.

\section{ROSTO E ULTRAJE}

Nossa breve exploração do conceito de rosto busca trazer visões de autores cujas perspectivas filosóficas ora tensionam, ora dialogam com a noção de rosto levinasiana, a saber: Gilles Deleuze e Félix Guattari (2004), com viés marcado fortemente pela reificação do humano no mundo pós-moderno; Giorgio Agamben (2000) e Régis Debray (1999), que ressaltam do rosto aspectos produtores de sociabilidade e de intersubjetividade; o rosto como fiel depositário da noção de comunidade. Ao tomarmos Lévinas $(2005,2011)$ como nosso principal interlocutor, enfatizamos uma compreensão do conceito de rosto como evento dialógico da alteridade, que se comunica através do rosto, configurando um clamor que nos invoca e instaura uma relação de responsabilidade. Nessa convocação do rosto como voz reside, para Lévinas, o evento originário da palavra, da comunicação.

Segundo Deleuze e Guattari (2004), diferentemente de Lévinas, o rosto é como a superfície lisa e moldável por agenciamentos que fazem parte de uma "máquina abstrata" social que rejeita tanto os rostos não-conformes quanto aqueles que tenham ares suspeitos (Lévinas, 2004, p. 44). Um rosto só se produz quando a cabeça se separa do corpo, e esse pode se revelar colônia da rostidade que descodifica, encapsulando-o como paisagem, por meio do processo de produção social do rosto. Sob essa perspectiva, o que hoje se vê circular nos discursos é uma hegemônica rostificação.

Já para Debray (1999, p. 227) o rosto é "a exposição indiscreta de um enigma: (...) aquilo que possuímos de mais comprometedor, de mais secreto, sendo também a parte mais perigosamente exposta de nós mesmos (...) Por meio de meu rosto eu confesso - sem saber o quê". Soma-se a isso a perspectiva de Agamben (2000) de que o rosto expõe e oculta o sujeito. No que é exterioridade para o outro, também se faz revelar a interioridade subjetiva, o que convoca o outro, como um apelo, um enigma. No reconhecimento do rosto é possível partilhar o que se vive e as relações que se constituem nesse viver. Segundo Agamben (2000, p. 99), "compreender a verdade do rosto significa tomar não a semelhança, mas a simultaneidade dos semblantes, a inquieta potência que os mantêm juntos e os reúne em comum". Assim, o modo de interação pragmática instaurada pelo rosto apresenta-se, ao mesmo tempo, como uma abertura à comunicabilidade e uma forma múltipla de expressões da comunidade. 
0 conceito de rosto na obra de Lévinas parece divergir em absoluto do conceito deleuziano. Lévinas (2011) propõe que 0 rosto se manifesta no face-a-face entre os homens e no gesto de acolhimento daquele que me antecede, do absolutamente outro e sobre quem também tenho responsabilidade. Os rastros que configuram o rosto envolvem, portanto, uma alteridade que nos remete à responsabilidade ética que se eleva contra as anulações individuais decorrentes das homogeneizações, das maquinações e das máquinas. Esse rosto, irredutível a uma composição biológica e fenotípica, defende-se das empresas, das técnicas e das instituições.

Argumentamos que a perspectiva de Lévinas escapa à rostificação quando situa o rosto fora do campo de visão, elevando a estética não reduzida à forma, mas ampliada pelo verbo. "Pode-se dizer que o rosto não é "visto". Ele é o que não pode se tornar um conteúdo, o que vosso pensamento abarcaria; ele é o que não pode ser contido, ele vos conduz ao além" (Lévinas, 2011, p. 57) Ao atribuir voz ao rosto, Lévinas localiza o aquém da imagem: "antes de ser imagem plástica e percepção sensível, de uma maneira mais essencial, o rosto é significação, fala; é por isso que a escuta do rosto prima sobre sua visão" (Poirié, 2007, p. 27). Esse apontamento evidencia os mecanismos de interlocução e, portanto, discursivos, que perpassam a subjetivação do que se constitui como rosto.

Ainda que Lévinas argumente a favor de um rosto que não pode ser contido na face humana - uma vez que o rosto é a presentificação da precariedade da vida, do sofrimento que não se deixa representar -, ele menciona que algumas expressões humanas podem ser significadas (substituídas por signos) a partir do rosto humano: figura que representa a dor, um clamor, uma demanda, uma finitude. Mas, ainda assim, a representação da face não dá conta de expressar o humano. Para Lévinas (1999), não há como uma representação imagética traduzir o "humano", pois a representação reduz os traços complexos do referente capturado, impedindo-nos de "escutar" o rosto (sofrimento vocalizado, por exemplo) através da imagem e afastando-nos da precariedade do outro. Contudo, Lévinas (1999) menciona tanto representações "plásticas" da face humana que obliteram o rosto quanto a possibilidade de o rosto operar e ser representado enquanto face, a partir do momento em que tal representação possa vocalizar ou ser entendida como resultado de uma voz que expressa um lamento, uma agonia, um sinal da precariedade da vida.

A perspectiva de Lévinas, a nosso ver, arremata o "enigma" (Debray) e o "estar-junto" (Agamben) dentro de um horizonte ético, respondendo criticamente a Deleuze e Guattari.

A partir disso, cabe ressaltar que o rosto feminino, em sua constituição no seio da cultura eurocêntrica, sofreu ao logo dos séculos diversas violações, entre as quais elegemos a modalidade do ultraje. Tal processo forjou-se alimentado pelos discursos falocêntricos; a histórica exposição pública discursiva e estereotipada dos rostos das mulheres tanto rostificaram, no sentido deleuziano, as identidades de gênero em torno de representações fixas, quanto interditaram o direito à palavra, dificultando a constituição das mulheres como interlocutoras.

Para Axel Honneth, o ultraje situa-se com uma das manifestações públicas do não-reconhecimento e da violação do outro. Ao partir das três dimensões hegelianas de reconhecimento intersubjetivo (o amor, o direito e a estima social), Honneth aborda as formas de desprezo reversas a tais dimensões, como as práticas de tortura, a supressão ou privação de direitos e a exclusão, além das ofensas sistemáticas e a desvalorização pública; "formas de não-reconhecimento que impedem a autorrealização completa do indivíduo, por violarem a integridade física, a integridade social e a moral (dignidade), respectivamente" (Mattos, 2006, p. 116). Como Honneth (1992) destaca, as faces do desprezo apontam danos diretos ou indiretos ao corpo, por exemplo: fala-se em morte psíquica para designar experiências de abuso sexual ou de tortura; em 
morte social quando há privação de direitos, como na situação de escravidão ou de marginalização; e - o que aqui nos interessa destacar - há ultraje quando está em jogo a dignidade, a reputação pública.

O ultraje designa uma agressão física, moral, social ou psicológica a alguém, a alguma instituição ou autoridade. 0 agressor se serve de terceiros como testemunhas do ato e que, como tais, venham legitimar o discurso e as práticas de quem ultraja, assujeitando o ultrajado a um juízo público que o diminui socialmente e perante si mesmo.

Discursos ultrajantes antifeministas são antigos. Em particular, na cultura medieval europeia a visão da mulher como animal (bestia) a vinculava ao signo da serpente ou de outra criatura venenosa. De acordo com Fonseca (2012, p. 169), "normalmente retratada como ciumenta e abrasivamente loquaz (virulentis sermonibus), a mulher era ainda uma consumista egoísta, frívola, dissimulada e de imbecilidade para o conhecimento e entendimento das coisas superiores ${ }^{5 "}$. Para 0 autor, a visão androcêntrica que atravessou os discursos misóginos ao longo dos séculos produziu na cultura ocidental uma ode à virgindade e ao celibato da mulher para que se garantisse a tranquilidade mental e espiritual do homem. A manutenção da virgindade era uma espécie de chancela que "livrava" as donzelas de abusos e das dores do casamento - e particularmente das fogueiras, para as quais eram conduzidas à força as "ameaçadoras bruxas" que rompiam com a fixidez do modelo medieval de feminino. Em suma, as mulheres eram "acessórias às disposições dos homens, vítimas dos seus comentários detratores e discriminatórios. Muitas vezes, o próprio elogio que a elas era feito constituía o fundamento de uma visão oposta, preocupada em conceituá-las más por natureza" (Delany, apud Fonseca, 2012, p. 183).

Seria possível reconhecer, ainda hoje, discursos antifeministas entre as imagens e as textualidades trabalhadas pela comunicação corporativa ou por outras mídias que a tomam os discursos organizacionais, e especificamente aqueles do estrato corporativo, como ponto de apoio para desenvolver suas enunciações quase medievais? Possíveis respostas para isso podem ser pensadas a partir do exemplo de Graça Foster na Petrobras.

\section{GRAÇA FOSTER: NOTAS ACERCA DE UM ROSTO ULTRAJADO}

0 que apresentaremos a seguir não constitui uma defesa de Graça Foster ou uma reflexão imparcial, que pretenda neutralidade diante do fenômeno investigado. Melhor seria dizer que o autor, por ser afetado pelo tema e por se sentir convocado pelo rosto da liderança feminina de Graça, procura problematizar as dimensões do que vê e do que haveria a ver para além do que é exposto. A partir daí nasce uma análise que remete a aspectos universais do rosto feminino, ancorada nas singularidades dos sujeitos de exploração - Graça Foster e o próprio autor.

A metodologia híbrida desenvolvida para a leitura qualitativa das produções midiáticas em questão alia elementos da análise do discurso a outros próprios da semiótica, considerando as dimensões ética e estético-expressiva das textualidades e imagens constantes nas produções analisadas. Compõem o corpus da análise capas de revistas (Veja, IstoÉ, Carta Capital, Você S/A), as primeiras páginas dos jornais de grande circulação (Folha de S.Paulo, O Estado de S. Paulo e $O$ Globo) e postagens online sobre Graça Foster (coletadas de diferentes fontes como blogs, sites de notícias como o portal UOL etc.), em momentos distintos de sua trajetória. A diversidade das produções reflete a intenção de

4 À guisa de exemplo, o episódio da história medieval francesa conhecido como "Ultraje de Anagni", ocorrido em 1303 na cidade de Anagni, Itália, resume a violenta disputa entre o então rei da França Felipe, o Belo, e o Papa Bonifácio VIII. Conta-se que o papa foi esbofeteado por um dos opositores italianos com a mão coberta pela luva de ferro. Sob a violência do golpe, o papa caiu do trono para o chão. Mesmo sob ameaça física, Bonifácio respondeu aos que pediam sua renúncia: "Eis a minha cabeça, eis a minha tiara: morrerei, é certo, mas morrerei papa". Fonte: http://pt.wikipedia.org/wiki/Atentado_de_Anagni. Acesso em 13/07/2015.

50 autor aponta pelo menos três literatos medievais como referências clássicas para o antifeminismo: Theophrastus (c. 372-288), São Jerônimo (Eusebius Sophronius Hieronimus, c. 342-420) e Walter Map (1140-c.1209). 


\section{ANO 13 • NÚMERO 24 • 1은. 2016 - ORGANICOM \\ ULTRAJE DO ROSTO: EMBATES DISCURSIVOS E RECONHECIMENTO DA LIDERANÇA FEMININA NA PETROBRAS}

compreender as tramas dicursivas que subjazem aos meios e os transcendem, interconectando-os linguageiramente, sem propriamente identificar um tipo discurso para cada produção.

Desde 2005, a Petrobras aderira ao Programa Pró-Equidade de Gênero ${ }^{6}$ e conquistara por três vezes o Selo Pró-Equidade de Gênero, concedido anualmente pelo programa às empresas que se destacam no cumprimento das metas relacionadas às Políticas para Mulheres. A iniciativa formalizou a política de igualdade de oportunidades na empresa para homens e mulheres de sua força de trabalho. Em 2012, após mais de 50 anos desde a criação da petroleira em 1953, uma mulher passa a ocupar seu mais alto cargo: Graça Foster. Sua posse simbolizava afirmação máxima da presença feminina num espaço historicamente ocupado por homens. Graça, diferentemente de seu antecessor, ingressara como estagiária em 1978 e construiu uma sólida carreira. Era esperada uma gestão "mais técnica, menos política".

A partir de então haveria fortes embates discursivos em torno da figura feminina da presidente, potencializados pelas denúncias de atos de corrupção envolvendo a empresa, mesmo anteriores à gestão de Graça Foster. Paralelamente, outro discurso organizacional, projetado pelo esforço de propaganda corporativa, procurava se fortalecer na imprensa, mas sem grandes repercussões. A Petrobras divulgava um balanço do número de mulheres na companhia; em nove anos a participação feminina cresceu $120 \%$, face ao crescimento de $60 \%$ dos homens no mesmo período ${ }^{7}$. Diante desse contexto, e dos discursos nele envolvidos, pode-se depreender que Graça presentificava o discurso de autonomia do rosto feminino no contexto organizacional da Petrobras, do que ressaltamos três dimensões: (1) sua notável trajetória de vida; (2) o justo reconhecimento profissional; (3) a consolidação e continuidade da liderança feminina em altos cargos de decisão ${ }^{8}$. Dessas três, parece-nos que a terceira tenha sofrido os mais fortes embates por discursos antifeministas, os quais contribuíram para a precariedade da posição política institucional assumida por Graça Foster, ameaçando sua sustentação no poder e, por procuração, o próprio discurso feminista sustentado pela comunicação corporativa. Embora não se possa atribuir à resistência ou violência de gênero a causa direta da renúncia da presidente, não se pode ignorar que essa tenha sido uma das variáveis fortemente presentes no processo de desconstrução da voz feminina no campo de decisão máxima da Petrobras. Além disso, é sabido que o rosto de Graça Foster inscrevia o rosto de outra mulher no comando da petroleira: o de Dilma Rousseff. Há uma conexão claramente identificável entre elas. Ambas as mulheres pioneiras nos cargos, reconhecidas publicamente por suas trajetórias pessoais e competências técnicas, mas distanciadas, ao menos perante a opinião pública, de um modus operandide se "fazer política" movido por negociações escusas e por corrupções de diferentes matizes.

0 ultraje seria o resultado da dissociação entre a dimensão deleuziana maquínica (máscara da gestora) e o rosto nu (a mulher, o feminino)? Quando Graça Foster, na dimensão de liderança, para além das competências técnicas e da trajetória pessoal, é sumariamente e publicamente julgada a partir de variáveis entendidas socialmente como próprias do feminino, vinculadas tradicionalmente ao universo da mulher, abre-se campo ao ultraje. Cremos que o ultraje moral ataca o feminino por meio da depreciação do rosto nu que inscreve a impossibilidade de Graça, como primeira mulher a assumir a presidência da Petrobras, oferecer uma contribuição coletiva efetiva à sociedade por meio de seu trabalho nesse cargo.

Na primeira imagem do Painel 1, veiculada pela revista IstoÉ Dinheiro em 27 de janeiro de 2012, dias antes de sua posse, Graça Foster aparece mirando a lente com um sorriso discreto nos lábios, cabelos alinhados, terno preto e camisa rosa; as vestes e

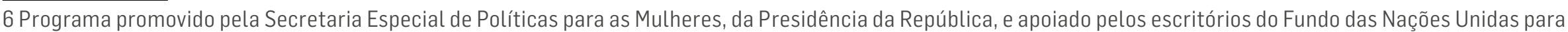
as Mulheres (Unifem) e da Organização Internacional do Trabalho (OIT).

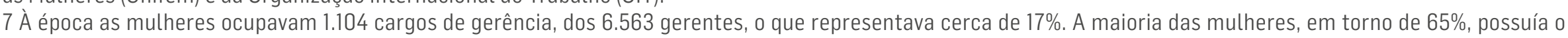

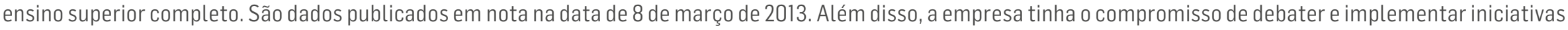
pela diversidade, como a produção de material pedagógico com conteúdos que incentivassem o combate à discriminação de gênero e raça.

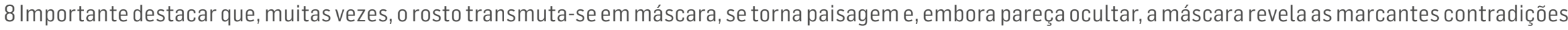

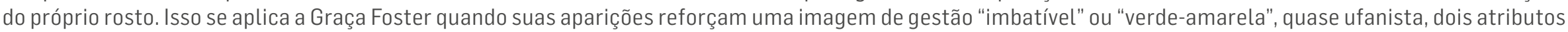

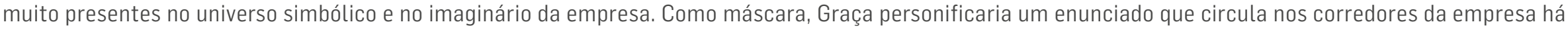
décadas: "Sou Petrobras: petróleo corre nas minhas veias!" 
os óculos de armação metálica equilibram a sobriedade de uma alta executiva com a cor amplamente explorada como traço de feminilidade na cultura capitalista. Nada muito avesso às visualidades tradicionalmente expressas na mídia ao se retratar mulheres ditas poderosas, não fosse a postura pouco formal de Graça. De pé, porém recostada numa parede de aço escovado, ela lança um olhar lateral para o espectador que culmina na cabeça ligeiramente inclinada para trás, num gesto corporal que destaca a linha dos seios, contrastando-se a vestimenta opaca com o fundo luminoso. Por um segundo temos a impressão de que esse mesmo gesto corporal poderia ser o de uma colegial, apoiada nos muros de uma escola à espera de um belo rapaz que a desvirginasse - uma atualização do tema renascentista da "morte da donzela"9. 0 somatório dos elementos visuais discursa sob o arquétipo da virgem; e, curiosamente, o texto da matéria traz a ideia da moça que saiu do borralho rumo ao trono. Mas felizmente por conta própria, sem direito à fada madrinha; a nova presidente é, de certo modo, heroína ${ }^{10}$. A legenda que acompanha a imagem a ideia de superação; ela apresenta uma confissão pessoal da mulher que nos olha, mais princesa que majestade.

\section{Painel 1: Graça Foster e a Petrobras:}

aparição do feminino entre o heroico e o erótico.
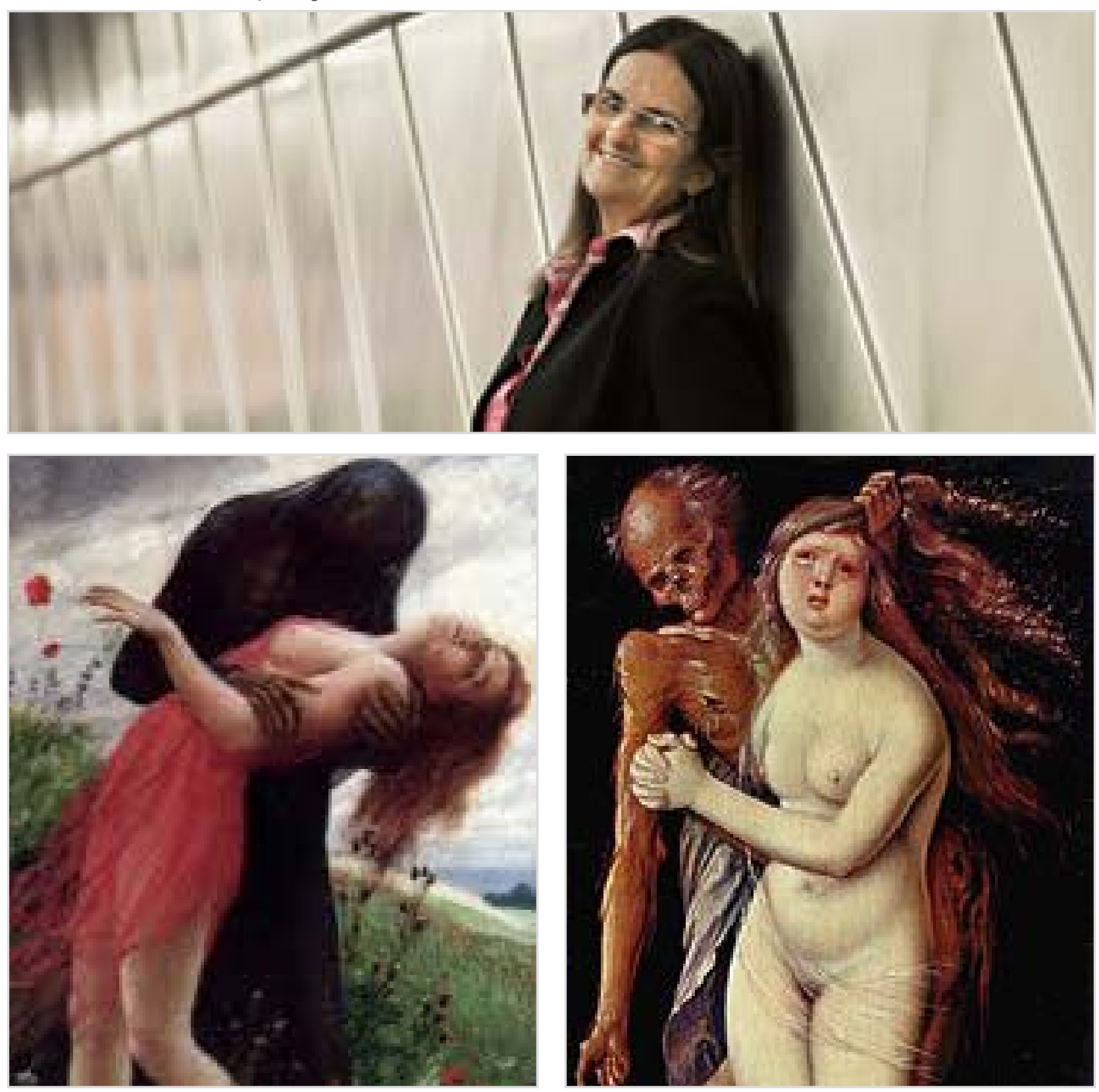

No alto: Graça Foster retratada pela IstoÉ Dinheiro (27/1/2012).

Embaixo: "A morte da donzela" em duas versões: Adolf Hering (1900, pintura a óleo; e Hans Baldung Grien (1517, têmpera). 0 aparecer da donzela vai da tortura ao gozo erótico em 400 anos.

9 "A morte e a donzela" é um motivo comum na arte da Renascença, especialmente na pintura e na música. Um proeminente representante é Hans Baldung Grien. 0 motivo foi usado novamente durante o Romantismo. Fonte: http://pt.wikipedia.org/wiki/A_Morte_e_a_Donzela. Acesso em 13/07/2015.

10 Ela cresceu no Morro do Adeus, que hoje faz parte do Complexo do Alemão, no Rio de Janeiro, ocupado pela polícia em 2010. Aos oito anos, começou a trabalhar como catadora de papel, garrafas e latas para ajudar a família e para comprar material escolar. Sem descuidar dos estudos, formou-se em Engenharia Química, fez mestrado em Engenharia Nuclear e MBA em Economia. 


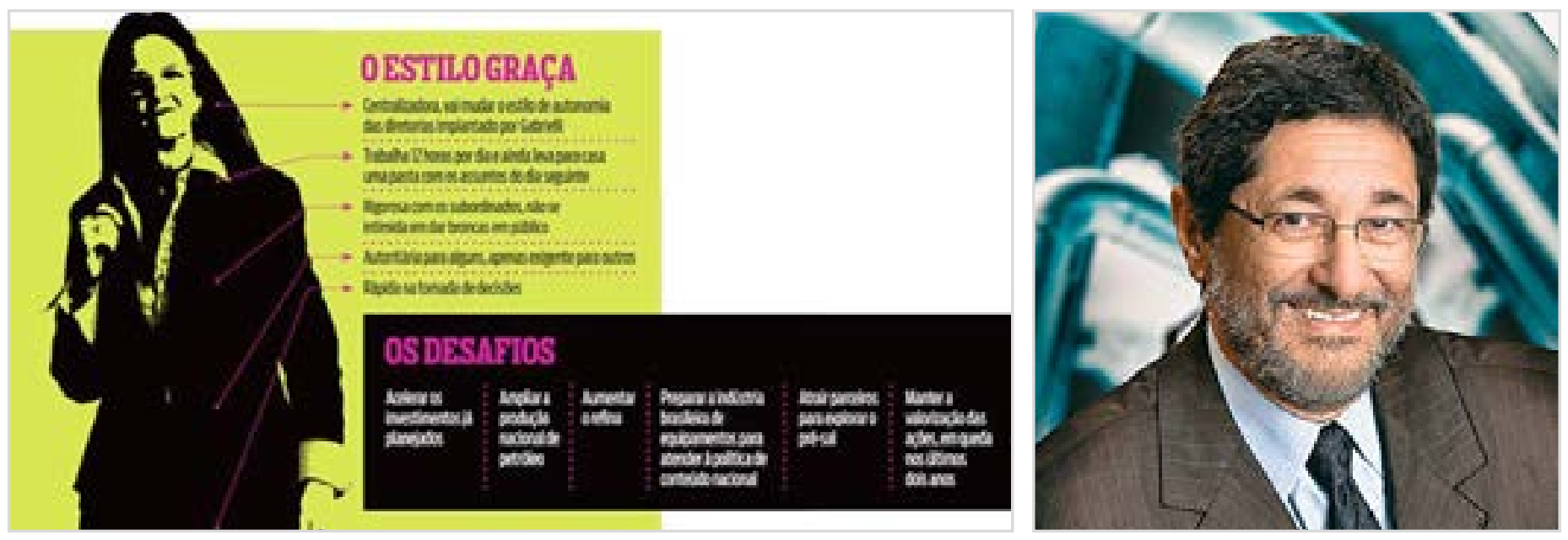

Infográfico "Estilo Foster" e fotografia de José Sérgio Gabrielli

Uma confissão que poderia ser a de muitas mulheres trabalhadoras da própria Petrobras, e mesmo de outras brasileiras: "A necessidade de superar a mim mesma me trouxe muita força e coragem". Graça Foster situa-se dentro do discurso mainstream segundo o qual alguém - especialmente uma mulher - alça uma poderosa liderança corporativa após enorme esforço e superação pessoais, a partir de uma longa jornada. Graça é um exemplo bem-sucedido do self-made man "de saias".

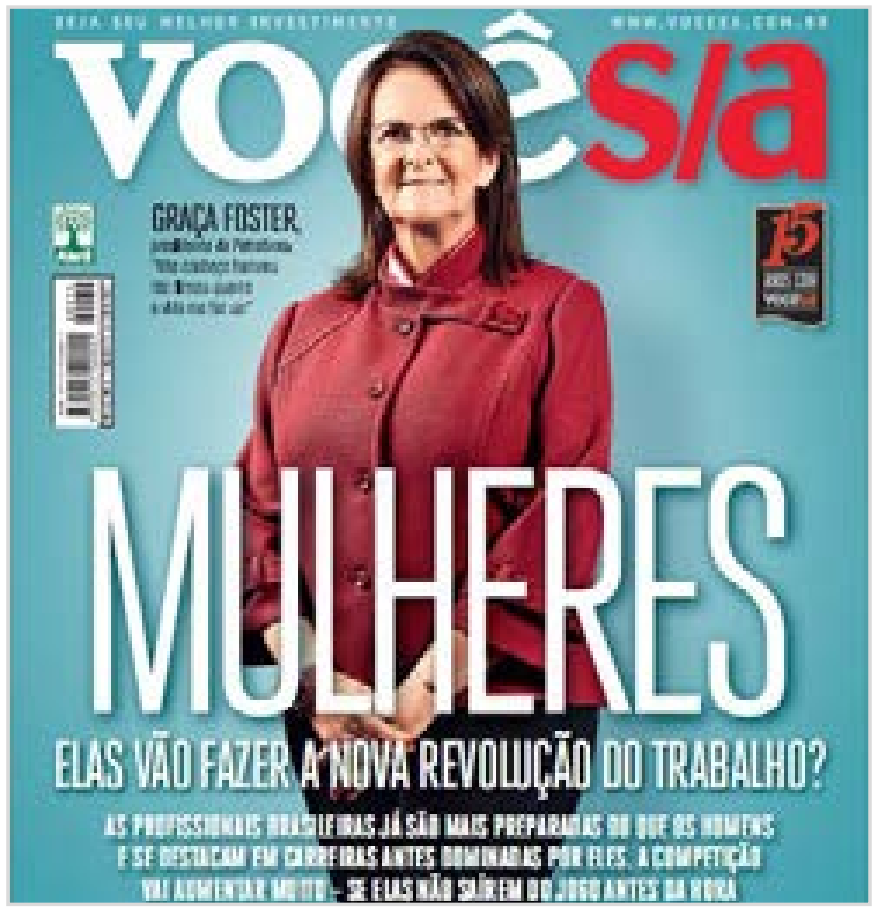

Capa da revista Você S/A (abril de 2013) destaca frase de Graça Foster: "Não conheço homens tão firmes como a vida me fez ser", evocando uma visão comparativa entre gêneros.

Ainda na primeira aparição de Graça Foster na IstoÉ Dinheiro, há referências ao "estilo Graça", desta vez apresentado por meio de infográfico nos tons verde e rosa, em que - aí sim - a figura estilizada da presidente aparece frontalmente, acompanhada por qualificativos que evocam elementos presentes nos manuais de "estilo e boas maneiras", publicação tradicionalmente direcionada ao público feminino (ver Painel 1). São destacados os seguintes traços de Graça Foster: centralizadora, rápida, trabalha doze horas por dia e "ainda leva demanda para casa"; rigorosa com seus subordinados, "não se intimida em dar broncas em público". 0 adjetivo "autoritária" aparece ao lado de "apenas exigente". Esse rol de atributos, visualmente desdobrados por setas que partem dos cabelos e das vestes de Graça reforçam a ambivalência de seu caráter feminino (autoritária versus exigente), bem como a "mãe brava" que não se exime de corrigir a prole em público; também a mulher incansável que traz para si as responsabilidades e que "dá conta" de tudo, mesmo que para isso seja necessária dupla ou tripla jornada. Ao que parece, o "estilo Graça" remete à dona de casa que administra uma empresa com a esperada habilidade "doméstica", exercendo 0 controle por meio de uma dedicação exaustiva, ora fálica, ora castradora, já que "Graça não tira férias há cinco anos". 
Já em 4 fevereiro de 2015, Graça Foster aparece nas capas da Folha de S.Paulo e do O Estado de S. Paulo (ver Painel 2) em uma imagem constrangedora. Flagrada ao passar pelo detector de metais do Aeroporto de Brasília, cabeça baixa, descalça, par de sapatos nas mãos, cabelos em desalinho, ela em nada lembra a executiva bem-sucedida de 2012. Como se sabe, no caso de violência física contra mulheres, os agressores ferem preferencialmente a face das companheiras para garantir marcas publicamente visíveis e Graça não passa ilesa. Segundo Janice Porto (2004, p. 112), o rosto da mulher que sofre violência "é marcado por olheiras profundas, o cabelo não é penteado e algumas vezes ajuda a esconder o rosto. Seu olhar é voltado para baixo e dificilmente olha nos olhos do interlocutor". O que se vê nessa imagem é um rosto feminino nu atingido por um ultraje. Havia muitos motivos para que a imprensa denunciasse uma possível "má gestão" da empresa ou mesmo apontasse críticas e falhas da administração Graça Foster. Mas o que se viu foi uma cascata de chamadas de capa ambíguas valendo-se do nome próprio feminino Graça como matéria-prima para máquina-imprensa de rostificação: "Dilma fica sem Graça" (Extra, 5/2/15); "Acabou a Graça" (Metro, 4/2/15), "Graça se foi... desgraça continua" (Estado de Minas, 5/2/15); "Bilhete sem volta para Graça Foster" (Correio Brasiliense, 4/2/15); "Sem Graça" (Zero Hora, 4/2/15).

Folha e Estadão também exploram um paralelismo inegável entre a imagem da presidente Graça Foster "deposta" e a execução do piloto jordaniano Moaz al Kasasbeh, prisioneiro do Estado Islâmico, queimado vivo. Nas capas há uma evidente "proporção visual" entre a imagem dos dois acontecimentos, conferindo maior violência ao ultraje do discurso da imprensa. Evocando a lição de Anagni, "do trono ao chão", a exposição do rosto ultrajado de Graça em primeira capa marca a ferro e fogo seu "triste fim". Ela já não é mais a donzela, mas uma "bruxa" que ameaça a sociedade e deve pagar por seus pecados, presentificados no corpo do jordaniano. 0 símbolo da indústria automobilística ocupa as margens de ambas as capas, como a lembrar que o mesmo fogo em que ardem os "criminosos" é aquele que alimenta a indústria mundial do ódio ao feminino - desde o medievo - e dos combustíveis fósseis, da qual a Petrobras é uma das maiores representantes. A punição simbólica de Graça Foster é a fogueira, talvez por sua inadequada pretensão em fazer-se soberana num cenário majoritariamente masculino e povoado por escândalos explosivos que podem colocar em risco mortal anos de trabalho, reputação positiva e, em última instância, o lugar feminino no contexto organizacional da Petrobras em situação precária. A mesma Graça que fora, durante o exercício do cargo, eleita pela revista norte-americana Fortune a executiva mais poderosa fora dos Estados Unidos, ficou em quarto lugar no ranking mundial.

Painel 2: Ultraje ao rosto feminino: renúncia de Graça Foster ou caça às bruxas?
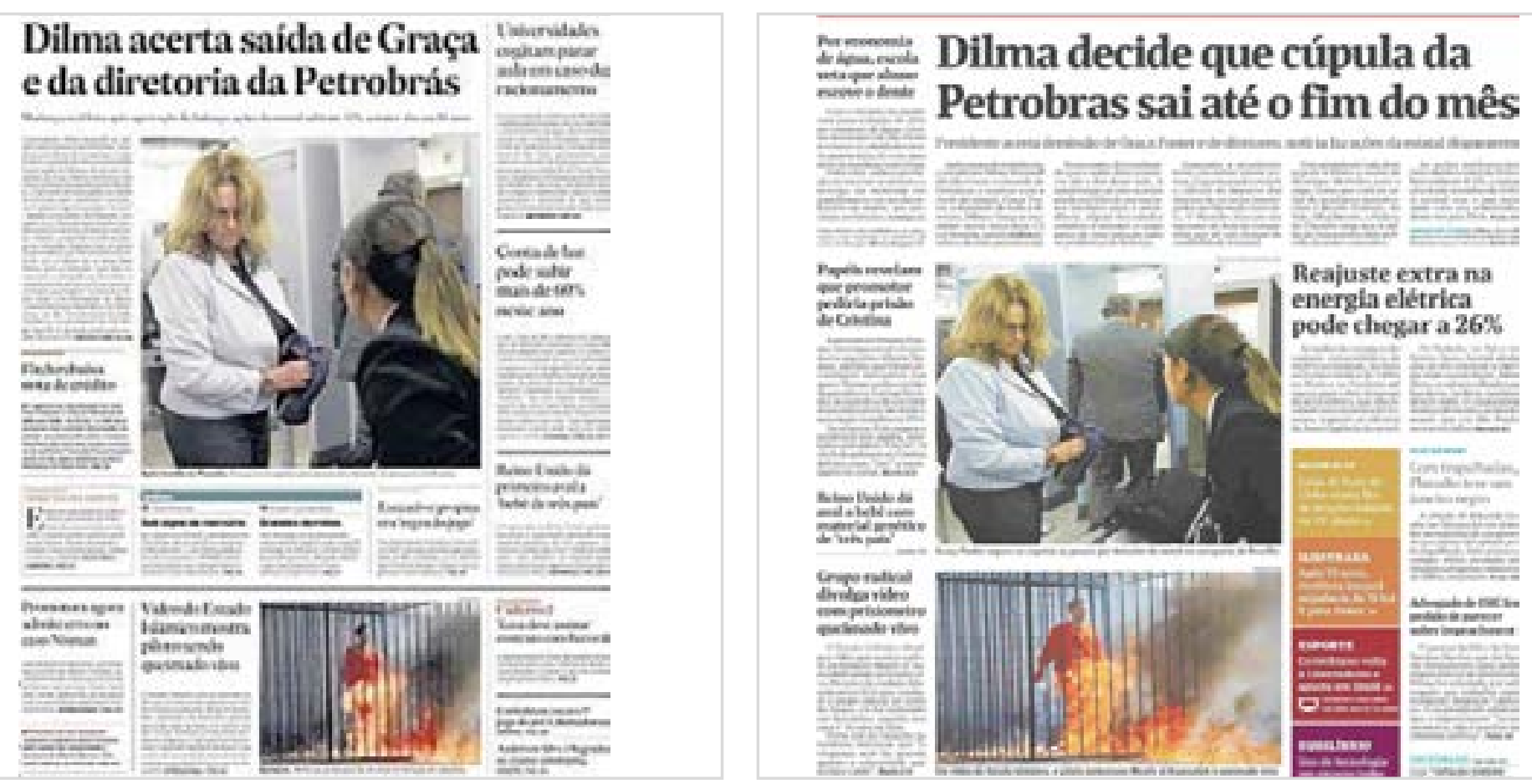

Ambas as capas de 4/2/2015 apresentam forte paralelismo entre o rosto ultrajado de Graça Foster e a espetacularidade da morte pela fogueira; o prisioneiro do Estado Islâmico, o piloto jordaniano Moaz al Kasasbeh é queimado vivo na mesma "proporção visual" em que Graça é apresentada ao público, "deposta", de cabeça baixa e descalça. Os carros, movidos a combustível fóssil, emolduram a narrativa, e arrematam o discurso antifeminista da imprensa. 
Finalmente, a virulência do ultraje atinge talvez seu paroxismo e uma das expressões discursivas mais peçonhentas vistas à época da renúncia, no mesmo nível dos abomináveis discursos medievais, embora revestida de "bom humor". A composição do Painel 3, publicada nas redes sociais da web, revela a máscara do predador. Sobre tal composição nos negamos a tecer comentários, uma vez que a textualidade acaba por desumanizar completamente o rosto feminino em favor de sua toxidez, esvaziando a ética perante outrem em favor do escárnio.

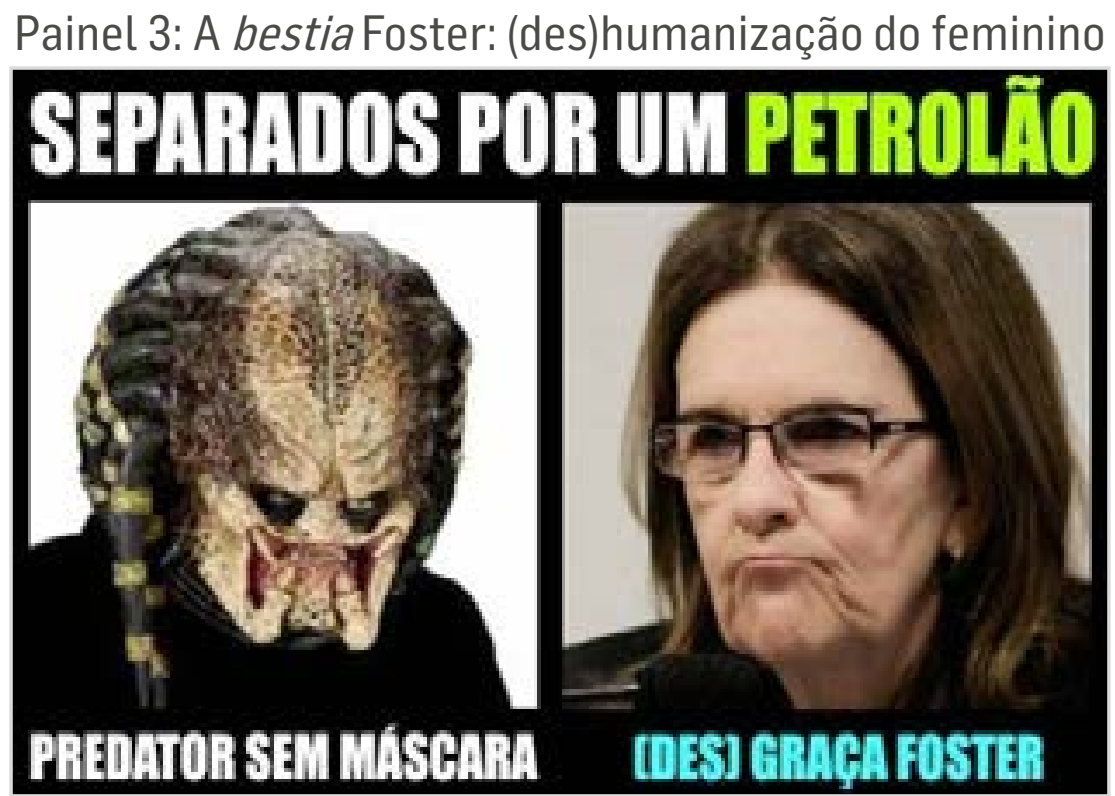

\section{CONSIDERAÇÕES FINAIS}

À guisa de breve conclusão, pode-se levantar como resultados da análise das produções destacadas neste artigo: (1) os discursos midiáticos sobre a figura de Graça Foster em grande medida estão alicerçados em crenças antifeministas que, de forma explícita ou implícita, contribuem para a rostificação dos rostos das mulheres brasileiras na mídia, em especial daquelas que se destacam como líderes do mundo corporativo e do mundo do trabalho; (2) a comunicação corporativa e, de modo mais amplo, a organizacional, pode reforçar os discursos midiáticos por meio do uso tácito de estereótipos do feminino, mesmo que, por vezes e em sentido contrário, as organizações se mostrem capazes de desenvolver políticas de gestão mais democráticas, que consideram a equidade de gênero, como é o caso da Petrobras. As imagens e os textos que circularam nas mídias massivas à época da posse de Graça Foster validam muitas das crenças machistas ao definirem, por exemplo, um estilo ou padrões para a liderança feminina; o que possivelmente a Assessoria de Imprensa da empresa endossou; (3) o ultraje é uma violência simbólica que visa atingir a reputação das lideranças para além de aspectos administrativos e de gestão corporativa.

Tal experiência de ultraje aqui relatada nos leva a pensar a comunicação organizacional, e especialmente a corporativa, a partir de um viés mais ético. Os discursos e as práticas organizacionais buscam, não raro, a valorização do todo em detrimento do rosto particular. É preciso provocar um tensionamento plural interno ao ambiente organizacional, desnaturalizando o que nos (a)parece comum, ou melhor, como um. Ela pode estar orientada para o reconhecimento do outro, que rompe com o assujeitamento da alteridade à mesmidade e, ainda, impõe limite ao agenciamento dos sujeitos ao império das imagens, num caminho comunicativo mais aberto à escuta, à receptividade que à totalidade presente na produção maquínica dos rostos.

Trata-se de romper com viés totalizante do discurso organizacional interno ou revelado na mídia, suspendendo sem romantismos o ultraje que estereotipa e enclausura as alteridades em identidades corporativas (máscara maquínica) pré- 
determinadas por preconceitos ou crenças limitantes. 0 grande desafio de romper com os agenciamentos maquínicos de ultraje e assujeitamento é investir no gesto de criar novos enunciados e cenas de enunciação capazes de permitir o surgimento de dispositivos, práticas e instituições que organizam a transversalidade entre macro e micro e promovem rupturas dentro da ordem discursiva dominante a partir das resistências cotidianas. Tais enunciados são o excesso que 0 poder vigente não tolera, o motor de lutas por reconhecimento que atravessam de um lado para o outro - do institucional ao vivido, da norma ao fato e à experiência -, convocando-os e constituindo-os como problema, de modo a criar as condições para a transformação e experimentação das relações de poder que os constituem.

\section{REFERÊNCIAS}

AGAMBEN, Giorgio. 0 rosto. In: Means without end: notes on politics. University of Minnesota Press: Minneapolis, 2000. p. 91-100.

BAKHTIN, Mikhail. Problemas da poética de Dostoievski. São Paulo: Forense, 1981.

. Observações sobre a epistemologia das ciências humanas. In: BAKHTIN, Mikhail. Estética da criação verbal. São Paulo: Martins Fontes, 2000. p. 399-414.

DEBRAY, Regis. Les matières de l'âme: le visage entre pierre et cyber. In: Croire, voir, faire: traverses. Paris: Jacob (Odile), 1999. p. 225-240.

DELEUZE, Gilles; GUATTARI, Félix. Ano zero: rostidade. In: DELEUZE, Gilles; GUATTARI, Félix. Mil platôs: capitalismo e esquizofrenia. Vol. 3. Trad. de Aurélio Guerra Neto, Ana Lúcia de Oliveira, Lúcia Cláudia Leão e Suely Rolnik. São Paulo: Editora 34, 2004. p. 31-62.

FAIRCLOUGH, Norman. Discurso e mudança social. Brasília: Universidade de Brasília, 2001.

FONSECA, Pedro C. Lousada. Fontes literárias da difamação e da defesa da mulher na Idade Média: referências obrigatórias. In: MASSINI-CAGLIARI, Gladis et al. (orgs.). Araraquara: Anpoll, 2012. p. 168-188. Disponível em: < http://portal.fclar.unesp.br/ poslinpor/gtmedieval/publicacoes/serie02_fontes/fontes_pedro-louzada.pdf>, acesso em 15/08/2016.

HONNETH, Axel. Luta por reconhecimento: a gramática moral dos conflitos sociais Trad. de Luiz Repa. São Paulo: Ed. $34,2003$.

- Integridad y desprecio: motivos básicos de una concepción de la moral desde la teoría del reconocimiento. Isegoría

- Revista de Filosofía Moral y Política, n. 5, p. 78-92, 1992.

LÉVINAS, Emmanuel. De outro modo que ser ou para lá da essência. Trad. de José Luiz Pérez e Lavínia Leal Pereira. Lisboa: Centro de Filosofia da Universidade de Lisboa, 2011.

. Alterity and transcendence. New York: Columbia University Press, 1999.

Entre nós: ensaios sobre a alteridade. Petrópolis, RJ: Vozes, 2004.

MATTOS, Patrícia. Sociologia política do reconhecimento: as contribuições de Charles Taylor, Axel Honneth e Nancy Fraser. São Paulo, AnnaBlume, 2006. p. 108-121. 
MORGAN, Gareth. Imagens da organização. São Paulo: Atlas, 1996.

POIRIÉ, François. Emmanuel Lévinas: ensaio e entrevistas. São Paulo: Perspectiva, 2007.

PORTO, Janice Regina Rangel. Violência contra a mulher. expectativas de um acolhimento humanizado. Dissertação (Mestrado em Enfermagem) - Universidade Federal do Rio Grande do Sul, Porto Alegre, 2004.

SILVA NETO, Belmiro R. da. Comunicação corporativa e a reputação empresarial. GV-Executivo, v. 12, n. 1, p. 22-26, jan.-jun. 2013.

\section{Sites consultados:}

http://economia.estadao.com.br/blogs/fabio-alves/2015/02/04/petrobras-compra-de-acoes/

http://fatosedados.blogspetrobras.com.br/2013/03/08/participacao-de-mulheres-na-petrobras-cresceu-120-desde-2003/

http://portal.comunique-se.com.br/index.php/jo-com/76333-graca-foster-x-petrobras-furo-da-folha-de-s-paulo-ganhacapa-de-impressos

http://www.istoedinheiro.com.br/noticias/economia/20120127/executiva-mais-poderosa-brasil/94333.shtml

Artigo recebido em 23.09.2015 e aprovado em 12.07.2016. 